\title{
PLANNING AND FINANCING SCHEMES LINKED TO THE DECISION-MAKING FOR THE INTERCONNECTION OF LONG-SHORT DISTANCE TRANSPORT
}

\author{
Eftihia Nathanail ${ }^{1}$, Giannis Adamos $^{2}$ \\ ${ }^{I}$ University of Thessaly, Department of Civil Engineering \\ Pedion Areos, 38334 Volos, Greece \\ Ph.: +30 24210 74164.Fax: +30 24210 74131.E-mail: enath@uth.gr \\ ${ }^{2}$ University of Thessaly, Department of Civil Engineering \\ Pedion Areos, 38334 Volos, Greece \\ Ph.:+3024210 74158.Fax:+3024210 74131.E-mail: giadamos@civ.uth.gr
}

\begin{abstract}
The development of interfaces between long and short distance transport networks is associated with the general processes planned by central governmental bodies; and the degree of their efficiency depends heavily on the successful cooperation among the involved planning stakeholders at various territorial levels. At the same time, no matter how efficient the planning process may be the lack of the appropriate financial planning and the coordination of the involved stakeholders for finding the required resources, affects the development of successful long and short-distance interfaces.

Towards this direction, the aim of the present paper is to investigate the planning and financing schemes developed in longshort interconnection in representative European countries, and assess how these processes are linked to the decision-making processes at a local, regional, national and European level. In addition, obstacles and barriers in the relative processes are indicated and methods for their alleviation are proposed.
\end{abstract}

Keywords: modal interconnection, terminal interfaces, decision-making, planning, financing, questionnaire survey

\section{Introduction}

Transport has gradually become one of the basic fields of concern of the European policy, with the White Paper "European Transport Policy for 2010": Time to decide" [1], representing the first comprehensive framework for the achievement of a sound European transport policy, and stating that the common transport policy has to be part of an overall strategy integrating sustainable development, including land use-planning policy, budgetary and fiscal policy, etc. [2]. In 2006, the Mid-review of the White Paper and the Communication "A Sustainable Future for Transport: Towards an Integrated, Technology Led and User Friendly System" [3], argued for a holistic approach to transport policy, taking into consideration that mutually complementary action is needed at national, regional and local levels of government, aiming at integrating investment needs, regulations, differentiated solutions, technological innovation and infrastructure development. The recently published (2011) by the European Commission White Paper "Roadmap to a Single European Transport Area - Towards a competitive and resource efficient transport system" [4] sets objectives and actions for the development of a more competitive and sustainable transport system till 2050, and includes initiatives for the elimination of significant barriers that obstruct the improvement of key sectors of transport, like infrastructure, investments and harmonization of legal frameworks.

Assessing the above policies and initiatives of the European Commission (EC), it can be stated that transportation is in an era of change. For the achievement of the objectives of the EC, sustainability in both passenger and freight transportation is required, and issues such as the integration of planning and financing processes, the coherent cooperation among local, regional, national and European stakeholders and the integration of efficient interfaces between short and long distance networks for the promotion of intermodality and limitation of road transport should be addressed.

Especially focusing on intermodality, the development of interfaces between long and short distance transport networks is associated with the general processes planned by central governmental bodies and the degree of their efficiency depends heavily on the successful cooperation among the involved planning stakeholders at various territorial levels. Issues such as environmental protection, energy conservation, modal split and competitiveness, improvement of accessibility and regulatory restrictions, affect the planning process, as well as the range and implementation of efficient interfaces. 
At the same time, no matter how efficient or integrated the planning process may be the lack of the appropriate financial planning and the coordination of the involved stakeholders for the finding of the required resources, affects the development of successful long and short-distance interfaces. The need for integrating the cooperation between the involved agencies and authorities, and establishing sensible financing schemes that improve the efficiency and flexibility of the processes, is crucial.

Towards this direction, and based on the research and work conducted till now in the framework of the FP7 project CLOSER (http://www.closer-project.eu/), the aim of the present paper is to investigate the planning and financing schemes developed in long-short interconnection in representative European countries, Spain, France, Norway, Finland, Czech Republic and Greece, and assess how these processes are linked to the decision making processes at a local, regional, national and European level. In addition, obstacles and barriers in the relative processes are indicated and methods for their alleviation are proposed.

For the achievement of the above aim, a survey was conducted, in order to collect data regarding the decision-making, planning and financing processes developed in each country, as well as at specific terminals involving long and short-distance interfaces.

\section{Method}

The methodology developed in the present paper includes review and analysis of the planning and financing processes developed in representative European countries, thus, Spain, France, Norway, Finland, Czech Republic and Greece, and refers to the interconnection of long and short distance transport networks. In addition, data was collected regarding the planning and financing schemes developed at specific terminals involving long and short interfaces.

In the first case, a template was used, including key points addressing the planning and financing procedures in each European country. Indicative aspects that were addressed when collecting information about the planning processes are the following [5]:

- Type of transportation plans developed, i.e. national, regional and local.

- Documentation of the transportation plans (i.e. objectives, responsibilities, involved actors, etc.).

- Public participation (if any) in the planning process.

- Regulatory framework.

- Consideration of environmental protection, energy consumption, safety and security, and social conscience.

- Assessment of relative barriers.

- Planning horizon, monitoring and assessment.

Similarly, the financing schemes developed in the above countries were identified, separated into two stages, thus, procurement/development, and management/operation.

In the second case, when investigating the planning and financing processes at specific European terminals, a questionnaire survey was conducted in order to collect the appropriate information. The questionnaire was filled in by the involved stakeholders during a face-to-face interview, and was structured into four parts. In the first part, information about the stakeholder and the terminal was collected, while the second and third parts included questions about the planning (i.e. responsible actors/stakeholders, public participation procedure, etc.), and financing (responsible actors/stakeholders, funding type, etc.) processes, respectively. Lastly, the fourth part of the questionnaire regarded the identification of barriers and the suggestion of methods for their alleviation.

\section{Illustration of Decision-Making Process in Europe}

Decision-Making (D-M) can be considered as the process, under the scope of which, the responsible bodies choose the "best" alternative for the planning, financing, time scheduling and implementation of a project, the content of a procedure, etc. Focusing on transportation, the "best" decision (solution) is usually the outcome of an integrated technical and economical approach and evaluation. Due to the wide range of both public and private bodies that participate, and the absence of a coherent legal framework applied in all transportation modes or possible combinations of them [6], the D-M in transport seems to be a rather complex process, and an "ideal"; thus, widely applicable framework is still under consideration.

A "Decision Makers Guidebook - DMG" [7], was produced in order to provide a methodology for D-M and is addressed to all categories of bodies involved in D-M processes, e.g., politicians, stakeholders, individual citizens, etc. According to the DMG, three approaches have been identified in Europe: 
the "vision led" approaches generated by an individual politician that visualizes specific future plans for the development of his/her municipality, region, etc., the "plan-led" approaches, which include a definition of objectives and an assessment of potential gaps or problems, before the establishment of a strategy and making of a (final) decision, and the "consensus-led" approaches that foresee relevant discussions among stakeholders for the development of the best strategy [8]. In addition, investigating, for example, the involvement of relevant public and private bodies in the urban transport planning, a diverse of stakeholders is observed, which can be generally beneficial to this stage of planning, although, the achievement of the participation of different interested groups that influence plans that are finally developed, remains difficult [9].

The frequency, the quality and the establishment or not of an integrated framework (e.g., periodic meetings, use of Internet, etc.), under which the previously mentioned discussions among stakeholders take place, before the final D-M, form the bases for the substantial (or not) public participation in the D-M processes. The DMG [8], defines five different levels of public participation; thus, "provision of information", "consultation", "deciding together", "acting together" and "supporting independent stakeholder groups" [9]. Nevertheless, the public participation, even if when it is well designed and despite the increased demand of people to have an active role in the D-M processes, cannot assure the success of any transportation project [10]. There are still, many problems and difficulties that have to be encountered for the provision of efficient transportation.

The CLOSER project, introduced a coherent decision-making (D-M) framework for the short-long distance interconnection, taking into consideration the wide range of the public and private bodies that are involved in the D-M processes. More specifically, it was defined that the strategic framework for shortlong distance interfaces, further specified as an integrated plan, is illustrated by planning and policy stakeholders, which are either considered separately or in accordance to the development of the needed infrastructure, and the system operation. The users, also, play a catalytic role and they affect the D-M process, at any level, i.e. strategic, tactical or operational [5].

The findings of the survey conducted in the framework of CLOSER, regarding the planning and financing schemes that are developed in long-short interconnection in European countries and specific terminals, are presented in the following paragraphs.

\section{Planning and Financing Processes in European Countries}

\section{Spain}

In 2005, the Plan Estratégico de Infraestructuras y Transporte 2005-2020 (Strategic Infrastructures and Transport Plan 2005-2020 - PEIT) was approved, dealing with the planning of all actions in the field of infrastructure and transport, and representing the largest ever drive to provide infrastructure in Spain (http://peit.cedex.es/). The Spanish Strategy of Urban Sustainable Mobility (EEMS) was approved in 2009 and was developed by the Ministry of Environment and the Ministry of Public Works and Transport, aiming at the establishment of a framework to orientate and provide coherence to the set of sectorial policies that are involved in the consecution of a sustainable mobility. In addition, the Spanish Strategy of Climatic Change and Clean Energy was created to accomplish the Spanish commitments regarding climatic change and to promote the use of clean energies with a focus on welfare, economic development and environmental protection (http://www.mma.es/secciones/cambio_climatico/ documentation_cc.estrategia_cc/pdf/cle_ene_pla_urg_mea.pdf).

In terms of intermodality, although this topic was not considered as a relevant issue in the national transport planning strategy, the last five years the PEIT has begun to recognize the importance of intermodality, and considered the need for integrating transport services and improving the collaboration among the different stakeholders, with the expectation to tackle some issues that have traditionally hindered intermodal integration up to this moment at national level. The PEIT pursuits the promotion of intermodality both for freight and passenger transport. In the first case, an Intermodal Goods Plan was defined dealing with issues like the structure of an intermodal network in Spain, the national and international intermodal corridors, the port, rail and airport intermodality, etc. In the case of passenger transport, PEIT developed an Intermodal Passenger Plan, with the aim to establish the basis for the intermodal passenger system, including timetable coordination, physical integration of the transport modes, the review of the framework of concessions for road transport of passengers, the introduction of systems to stimulate competition and quality, and the promotion of "shuttle" bus services between population centres of a certain size and airports and stations with high-performance services, etc. (http://peit.cedex.es/).

Lastly, focusing on financing, strategies included in the PEIT, refer to the National budget, which should remain the main source of the financing transport infrastructures and the promotion of the private section participation through Public-Private Partnerships. 


\section{France}

The transportation planning system in France is developed under three levels, thus, national, regional and local planning, and the associated financial schemes should obey to the overall negotiation that leads to the planning processes.

More specifically, at a national level, the National Scheme for Infrastructure synthesizes national priorities and investment priorities of the regions, through a procedure of contractualisation among the central state and the each region. At the regional scale, following the first acts of Decentralization (1982), the linking of transport and spatial planning was solely achieved through the "Contrats de Plan Etat Région" (Territorial Coherence Schemes - SPER). These schemes, lasting 5 to 7 years, set out decisions made in terms of transport facilities, with the central government's decision being dominant (http://enseignementsup-recherche.gouv.fr/cid5758/les-contrats-de-projets-etat-region-c.p.e.r.-

2007-2013.html). This strategic plan foresees that the connections between transport and land planning are explicitly defined at regional level, but the regions lack some of the levers needed to ensure coordination of spatial policies.

On the other hand, the municipalities remain in control of land use planning, and this causes unbalance to the coherence of the different levels of authorities, therefore the "Schémas Régionaux d'Aménagement et de Développement du Territoire" (Patterns of Regional Development and Territorial Development - SRADT) must oversee the coordination of the various "Schémas de Cohérence Territoriale" (SCOT), but the latter do not have to follow regional choices, and links between the Urban Transport Plans (PDUs) and the SRADTs do not exist. Regarding PDUs, these should be compatible with the SPERs that define the general orientations for the urban territory. In this context, recent French legislation has encouraged planning which links transport and spatial planning at two levels: on one hand, the conurbations with the authorities responsible for urban transport charged with creating PDUs and the municipal associations responsible for SCOT; on the other hand, the regions, which draw up "Schémas Regionaux de Transport" (Regional transport schemes - SRTs) within the framework SRADTs.

\section{Norway}

The Norwegian National Transport Plan (NNTP) for the period 2010-2019 is the central document for the transport sector in Norway, produced every four years, and elaborating on how the Government should prioritise resources in transport over the next ten years. The relative processes are led by the Ministry of Transport and Communications, and other stakeholders involved are county councils, and road, rail, aviation, sea and municipal authorities. The NNTP may focus on the strategic level of the decision making, though large infrastructure projects are also included in the specific plan.

In addition, the Planning and Building Act foresees that public planning should promote sustainable development and public participation. The Ministry of Environment is the dominant administrative responsible for the national planning and monitoring of the Act, while the county planning has to be documented in Regional Master Plans, which are obligatory for all municipalities (http://www.lovdata.no/all/nl-20080627-071.html). Counties also make county transport plans, and they may cooperate, either with other counties on larger regional transport plans or with city areas in the development of urban transport plans, respectively.

As far as financing is concerned, the main post at the state level is the annual National Budget (http://www.statsbudsjettet.dep.no/upload/Statsbudsjett_2010/dokumenter/pdf/gulbok.pdf). Building and maintenance of state roads are financed by the National Budget and tolls, including some cases of PublicPrivate Partnerships. Both investment and maintenance of rail infrastructure are financed at a national level, over the National budget, while aviation infrastructure and terminals are financed through aviation taxes and commercial incomes. The ownership status of terminals defines financing, for example, harbours/ports are owned by municipality, bus terminals are mostly owned by county or municipality (in cities), although in some cases still owned by the local bus company, etc.

\section{Finland}

In Finland, for large projects that have national importance and state funding, the initiative for planning is developed by the Ministry of Transport and Communications. The plan is then further developed in the Transport Agency together with the regional authorities i.e. cities or other municipalities.

Focusing on regional planning, the Regional Land Use Plan defines the use of areas needed for particular purposes and the principles of urban structure in accordance to the regional development. The next step foresees that the planning proceeds to a more detailed Master Plan for each region, thus the Town Plan. The regional authorities, cities and other municipalities forming the Regional Councils, 
together with the state authorities i.e. Centres for Economic Development, Transport and the Environment are responsible for the planning. Transport planning is a part of the general planning procedure, i.e. Land Use and Building Act 132/1999, amendment 222/2003 (http:/www.finlex.fi/en/laki/kaannokset/1999/en 19990132.pdf); Land Use and Building Decree 895/1999 (htpp://www.finlex.fi.en/laki/kaannokset/1999 /en19990895.pdf), and Decree on the Openness of Government Activities and on Good Practice in Information Management 1030/1999 (www.finlex.fi/pdf/saadkaan/ E9991030.PDF), etc.

Among the plans concerning transport is the national strategic plan "Transport 2030 - Major Challenges, New Directions" prepared by the Ministry of Transport and Communications, and included a wide-range public consultation that was carried out in the regions. The aim of the specific plan was to stimulate a broad-base discussion regarding the direction and framework of transport policy, in order to be used for the documentation of an action plan that will set out the critical measures required for the next ten years and to specify the appropriate measures for the integration of the transport system (http://www.lvm.fi/fileserver/transport\%202030.pdf).

As regards the transport financing schemes, the maintenance of public roads, railways and maritime and inland waterways is financed by central government resources, while major transportnetwork development projects are decided by Parliament. Such projects are granted a single contract authorization covering all the project's construction costs. New projects are included in the Government's budget under the item for transport network development.

\section{Czech Republic}

In 2005, the Czech Government approved a new Czech Republic's Transportation Policy for 2005-2013 that sets strategic goals for transport and transportation networks under the scope of the full Czech membership in the EU, including priorities such as the improvement of transport safety, the support of regional transport development, the assurance of financing transport, the provision of high quality transport infrastructure, etc. (http://www.mdcr.cz/en/HomePage.htm).

In addition, the Operational Programme Infrastructure (OP Infrastructure) for the programming period 2004-2006 was developed in compliance with EU regulations and works as the main document regarding the cohesion of transport policy in Czech Republic, formulating seven priority axes; thus, axes 1 and 3 for railway modernization, axes 2 and 4 for highways and first class road construction, axis 5 concerning subway and transport operational system development in Prague, axis 6 for multimodal freight transport and river transport development and axis 7 regarding technical assistance. Most of the approved projects were submitted under the 4th axis and the highest shares of funding were allocated in projects of the axes 1 and 2 (http://pernerscontacts.upce.cz/18_2010/ Hajek.pdf).

From the side of financing, transport infrastructure investments and sustainable transport are funded by the EU cohesion policy for the period 2007-2013. The relevant budget for the Czech Republic is distributed among eight sectoral operational programmes, seven regional operational programmes (ROPs), six operational programmes of the European Territorial Cooperation objective and two operational programmes designed for Prague. In this framework of the operational programmes, an important priority was given to transport (http://www.mdcr.cz/en/HomePage.htm).

\section{Greece}

The current and future planning and financial processes and schemes in the transport sector in Greece are part of the National Strategic Reference Framework (NSRF) of the period 2007-2013. The Ministry of Economy and Finance (MEF) is responsible for elaborating the NSRF proposal for 2007-2013 and for coordinating all relevant procedures. In the framework of NSRF, the programming documents regarding the transport sector include the Operational Programme "Accessibility Improvement", the "Transports Development Plan 2007-2013 and twenty-year plan", and the National Port Policy (11).

The Operational Programme "Accessibility Improvement" 2007-2013 (OP-AI) includes interventions that enhance the improvement of accessibility both regionally and internationally (i.e. transEuropean interconnections). For example, in the road sector, emphasis is given to the continuation of the construction of the PATHE and Egnatia motorways, the promotion of combined transport through the implementation of the Trans-European Network for Motorways and the improvement of the regional road network and interconnections of transport networks (11). On the other hand, the main objective of the Transports' Development Plan (TDP) 2007-2013 is to formulate a documented basis for the documentation of a long-term development vision, setting focused priorities such as the integration of a national transportation system, the promotion of the country as the central node of South-Eastern Europe and connection link of East Mediterranean and the implementation of an improved (re)structuring of 
the planning, control and surveillance transport system (12). Lastly, the National Port Policy (NPP), formulated in 2006 by the Ministry of Maritime Affairs, Islands and Fisheries, highlighted the need for improving productivity, efficiency and quality of the provided services, the adjustment of the maritime system into dominant transportation trends and needs, the establishment of a friendly and flexible business environment, and the harmonization and efficiency of the private maritime settlements and ports of the country (13).

Regarding the financing processes in Greece, the majority of the transportation projects are cofinanced from EU, as well as from national resources (for example in cases of expropriations, etc.). In addition, private funding of projects is also foreseen. Other funding schemes developed in specific transport investments and projects are the Public-Private Partnerships (PPPs) and joint ventures. The funding process of transport projects is based on their classification in three categories. Projects of priority A are proposed for funding in the programming period 2007-2013, projects of priority B are also proposed for funding in the programming period 2007-2013, and projects of priority $\mathrm{C}$ are proposed for funding in the next 20 years (11).

\section{Planning and Financing Processes in Specific European Terminals}

The findings of the questionnaire survey conducted in the specific European terminals are presented in the following paragraphs, under five pillars: railways, ports, airports, bus terminals and freight terminals.

\section{Railways}

The first terminal refers to the Hellenic Railway Organization (OSE S.A.), which is a stateowned organization, providing rail passenger and freight services. National authorities are responsible for all stages of the planning and financing processes. Regarding the developed financing schemes, in the cases of land acquisition, engineering and construction, the funding comes from direct investment and European funds, while management, operation/maintenance and control relies on direct investment, only. It has to be mentioned that all companies have an equal access to the terminal.

The second terminal regards the rail terminal Bratislava in Czech Republic, in which the national rail manager of infrastructure (Železnice Slovenskej republiky - ŽSR) owns the infrastructure, and the national rail operator (Železničná spoločnost' Slovensko a.s. - ZSSK) operates the station. The City Council and the Regional Municipality are, also, involved in the planning processes. More specifically, regarding the planning process, national, regional and local authorities and private actors, responsible for taking initiatives for investments, national, regional and local actors are involved in the stages of technical specifications, evaluation/selection and procurement, while the feasibility study and construction are under the supervision of private actors. In addition, customers and demand side actors are responsible for the operations and maintenance, national and local authorities for the regulations, while in the case of exploitation and ownership, land is under the responsibility of national regional/local actors, infrastructure under national authorities and private actors, and operations under private actors, respectively. As far as the financing processes are concerned, national, regional and local authorities are responsible for land acquisition, which is directly invested, while the engineering/design, management and operation/maintenance are under the responsibility of private-private partnerships (PPPs) and are also directly invested. In construction, national and regional authorities, as well as PPPs are involved, while funding, in this case, is made through direct investments, PPPs and European resources. Regarding control, this stage is under the scope of regional and local authorities and is funded by deferred investments. Lastly, it has to be noted that all operators have an equal access to the terminal, while the most important barriers that may occur are dealt with in the planning process.

\section{Ports}

Examining the planning and financing processes in Thessaloniki Port Authority S.A. (ThPA S.A.) in Greece, the port works under a concession agreement between the state and the ThPA S.A, according to which ThPA S.A. has the exclusive right to use and exploit land, buildings and facilities of the port, owed by the state. All stages of the planning process are under the responsibility of the ThPA S.A., expect the regulatory framework, which is under the scope of the state. Regarding the financing process at the port, all stages are under the responsibility of ThPA S.A., and the funding scheme is exclusively direct investment. Also, the public participation is foreseen through the submission of proposals to the Ministry of Mercantile Marine and Aegean Sea, the announcements to ThPA S.A. website for public consultation, occasionally consultation with the Municipality, while international and national public tenders for procurement are also foreseen, in accordance with the European legislation. In addition, it has to be 
mentioned that, in the case of big infrastructure projects, the ministry of Mercantile Marine and Aegean Sea, has to coordinate with the procedures for the issuance of Common Ministerial Decisions, and in case of international calls for tender with budget over 1.000.000 euros, a ruling Court of Auditors is requested before the signing of the contract. All decisions are made by the ThPA S.A. board of Directors. Finally, the most important barriers, both in planning and financing processes, refer to finance and legislation.

In the case of the Norwegian Coastal Administration, which is the national agency for coastal management, maritime safety and communication in Norway, the initiative for investments, procurement and feasibility study are under the responsibility of national and regional/local authorities, the technical specifications and the regulatory framework under national authorities, the construction under private actors, the evaluation/selection under national, regional and local authorities and private actors, and the operation/maintenance under regional/local and private actors. In the stage of exploitation/ownership, regional and local authorities are responsible for land, and national, regional and local authorities for operations. In terms of the financial process, the state is involved in all stages, while regional and local authorities are responsible for engineering/design, construction, management, operation/maintenance and control. Customers and actors from the demand side are also involved in the stages of construction and operation/maintenance. Also, the financing scheme that is developed in all stages of the financial process is direct investments, and PPPs in the cases of engineering/design, construction and operation/maintenance. Lastly, it has to be noted that public participation is formally ensured through hearings and meetings with stakeholders in the early stages of the planning, while important barriers are indicated in the coordination and initial stages of the planning process.

\begin{abstract}
Airports
Investigating the planning and financing processes from the side of airports, the first terminal regards the Oslo Airport Gardermoen, in Norway, in which, the Oslo Airport LTD and the mother company Avinor LTD, are responsible for all stages of planning, excluding operation/maintenance and regulatory framework, which are under the authority of the Oslo Airport. As far as the financing process is concerned, Avinor LTD is responsible for the funding of land acquisition, engineering/design, construction and management, while the Oslo Airport is involved in engineering/design, construction, management, operation/maintenance and control. The land acquisition is funded through state and private loans, while the resources for engineering/design, construction and management are provided by the state and private loans and direct finance from the Oslo Airport. Oslo Airport also finances operations and maintenance.

The second air transport terminal refers to the Prague Airport Ruzyn, which is a joint stock company. The exclusive responsibility of initiative for investments, technical specifications, procurement and evaluation/selection is under national authorities, while the feasibility studies, construction and operation/maintenance is under private actors, respectively. The regulatory framework is under the scope of national and regional/local bodies. In terms of exploitation/ownership, the part of land in under the supervision of national authorities, and the infrastructure and operations are under national, regional and local actors. Regarding the financing process, national authorities are involved in land acquisition, construction, management and control, and PPPs in all stages. Specifically focusing on land acquisition, engineering and management, the financing scheme is direct investment, in construction and operation/ maintenance the scheme is direct investment and PPPs, while control is funded by deferred investments.
\end{abstract}

\title{
Bus terminals
}

From the scope of public transport, in the Urban Pubic Transport Organization of Thessaloniki, Greece, the national authorities are involved in the technical specifications and the infrastructure part of the ownership, and the regional/local authorities in the regulatory framework, land and infrastructure. Also, private actors are responsible for all stages of the planning process, except of the regulatory framework and the construction in which manufactures are involved. As far as financing concerned, regional and local authorities are involved in land acquisition, engineering/design and construction, and PPPs in all stages. The funding of land acquisition is under direct and indirect investments and PPPs, while all other stages are funded via direct investments. The most significant barriers indicated in the specific organization regard coordination and legislation in the planning process, and resources finding in the financing planning process.

In Czech Republic and the Brno bus station, two categories of actors involved in the planning process are identified: regional/local authorities and private actors. The first category is indicated in the initiative for investments, technical specifications, procurement, feasibility study, evaluation/selection, 
regulatory framework and land in exploitation/ownership. On the other hand, private actors are involved in initiative for investments, procurement, feasibility study, construction, operation/maintenance, as well as in the sectors of infrastructure and operations in the stage of exploitation/ownership. In terms of financing and the relative allocation of responsibilities among the involved actors in the specific terminal, national and regional authorities are indicated in land acquisition and engineering/design, and PPPs in the rest stages, thus, construction, management, operation/maintenance and control. The funding scheme in land acquisition is direct investment, in construction European funds and PPPs, while the rest stages of the process are financed via PPPs. Lastly, it should be noted that the most important barriers are indicated in coordination and control in the planning process, and in resources finding and control in the financing planning process, respectively.

\section{Freight terminals}

The last terminal investigated in the present paper regards the private freight terminal SINDOS S.A., in Greece. Due to the private status of the terminal, private actors are mostly involved in all stages of the planning process, excluding the regulatory framework and the evaluation/selection, for which national authorities are responsible. National authorities are also met in the state of the stage of initiative for investments and procurement. Regarding the financing process, the responsible actors are either national authorities, i.e. land acquisition, engineering/design and construction, or PPPs in all stages. Direct investments are developed in all stages of the financing process, and European funds, are, also, used for land acquisition, engineering/design and construction. It has to be mentioned that during the planning process, procurement and terms of reference had been published widely and tenders were invited. Also, the selection of the property on which the terminal was developed was based on the existing land uses, established by the national regulations (i.e. industrial zone), and the specific site was selected so as to have direct access to the national highway network and the main railway network, which had to be expanded by the developers. Finally, the most important barriers are indicated in legislation.

\section{Summary and Discussion}

The aim of the present paper was to investigate the planning and financing schemes developed in long-short distance interconnection in representative European countries, Spain, France, Norway, Finland, Czech Republic and Greece, as well as in specific European terminals, and to assess how these processes are linked to the decision-making processes at a local, regional, national and European level. For the assessment of the commonalities and differences in the above processes in the case of the European countries, a template was developed including key points addressing planning and financial processes in each country, while, in the case of terminals, a questionnaire survey was conducted, addressing issues such as the identification of the involved stakeholders, public participation, funding schemes, indication of barriers and suggestion of methods for their alleviation, etc.

Analysing and assessing the data collected for the planning and financial processes in the representative countries, it was indicated that the strategic scheme of the planning processes followed in the long and short-distance interfaces is usually a "National Transportation Plan - NTP, with a time horizon usually 10-30 years. The Ministries of Transport are the main responsible bodies for the preparation and coordination of the NTPs. In case that the NTP is part of an Operational Programme (OP) (as in Greece for example) then, apart from the ministry, the relative managing authorities of the OP play also a significant role in the preparation and management of the NTP. As far public participation is concerned, it is common an "open" procedure (on-line call for proposals, etc.) to be followed before the finalization of the NTPs. Investigating the planning schemes at a regional level, common processes were also observed, e.g., the preparation of Regional Transport Plans (RTPs), which are usually parts of the NTPs, though focusing on regional needs. At an urban or local level, most of the large cities in European countries, prepare Urban Mobility Plans (UMPs), focusing on providing daily services to users (i.e. comfort, safety, etc.).

Regarding to the planning schemes identified at specific terminals, these vary from country to country and from mode to mode. In general, the status ownership (private, stated-owned, public-private, etc.) sets the parameters both for the planning and financial processes, while EU and national legislation also affects the preparation and implementation of the plans at passenger and freight terminals. The planning time horizon is usually 10 years, and the content of the plans is strongly dependent on the location (topography and technical appropriateness, complementary activities in the surrounding areas, etc,), as well as of the accessibility of the terminal (distance from ports, airports, railways, urban and commercial centres, nearest highways, etc.). 
Finally, the review of the financial processes followed in European countries, showed that majority of transportation projects are co-financed by EU, as well as by national resources and private funding (example.g., in cases of expropriations, etc.). The relative plans, i.e. NTPs, RTPs or UMPs, may define the allocation of co-funding of the projects. The main responsible for the financial management is the responsible ministry of finance and economy in each country, which has the general supervision and sets the priorities in funding several projects. A rather expanded funding scheme in EU countries is PublicPrivate Partnerships (PPPs), thus, types of cooperation between the public and private sector based on a contract between the two bodies.

The most significant problems that were met in the above countries and terminals are related to the involvement of more than one body in the planning and financing stages of the decision-making process in the interconnection of long-short distance transport, and the relative conflict of interests of the involved stakeholders. Potential solutions for the alleviation of these problems include the establishment of a well documented cooperation among the involved stakeholders, the distinction of ownership status from operation for the insurance of the equal access to all, and the pursuance of Public-Private Partnership models for the confrontation of complex local and regional problems and financing issues.

\section{Acknowledgements}

The present paper is based on the research that has been conducted till now in the framework of the CLOSER project (Connecting Long and Short-distance networks for Efficient tRansport), which is co-funded by the European Commission within the $7^{\text {th }}$ Framework Programme. The authors would like to thank both the consortium of the project and the European Commission.

\section{References}

1. European Commission. (2001). European Transport Policy for 2010: time to decide. White Paper. CEC.

2. Commission of the European Communities. (2001). COM (2001) 307 final. European Transport Policy for 2010: time to decide. European Communities, Brussels.

3. European Commission. (2006). Keep Europe Moving. Sustainable mobility for our continent. Midterm review of the European Commission's 2001 transport. White Paper. ISBN 92-79-02312-8. Luxemburg: Office for Official Publications of the European Communities.

4. European Commission. (2011). COM (2011) 144 final. Roadmap to a Single European Transport Arena - towards a competitive and resource efficient transport system. White Paper. European Commission.

5. Nathanail, E., Adamos, G., Parra L., Ruiz-Ayucar, E., L' Hostis, A., Blanquart, C., Olsen, S., Christiansen, P., Osland, O., Järvi, T., Svedova, Z. \& Zan, B., (2011). Analysis of the DecisionMaking Framework. In E. Nathanail \& G. Adamos (Eds.) Deliverable D4.1. CLOSER - Connecting LOng and Short-distance networks for Efficient tRansport. CLOSER Project. Brussels, Belgium: CLOSER Consortium.

6. Adamos, G., Nathanail, E. \& Zacharaki, E. (2012). Developing a Decision-Making Framework for Collaborative Practices in Long-Short Distance Transport Interconnection. Procedia - Social and Behavioral Sciences, Volume 48, 2012, pp. 2849-2859, Elsevier.

7. May, A. D., Karlstrom, A., Marler, N., Matthews, B., Minken, H., Monzon, A., Page, M., Pfaffenbichler, P. C., Shepherd, S. (2003). Deliverable $N^{o}$ 15. Decision Maker's Guidebook. PROSPECTS Project. Brussels, Belgium: Prospects Consortium.

8. Emberger, G., Pfaffenbichler, P., Jaensirisak, S. \& Timms, P. (2009). Ideal decision-making processes for transport planning: A comparison between Europe and South East Asia. Transport Policy, 15, 341-349.

9. Ward, D. (June 2001). Stakeholder involvement in transport planning: participation and power. Impact Assessment and Project Appraisal, 19(2), 119-130.

10. Szyliowicz, J. (2003). Decision-making, intermodal transportation, and sustainable mobility: towards a new paradigm. Oxford, UK: Blackwell Publishing, Ltd.

11. National Strategic Reference Framework (NSRF) 2007-2013, Hellenic Republic, Ministry of Economy and Finance, General Secretariat for Investments and Development, Athens, Greece, 2007.

12. Transports' Development Plan (TDP) 2007-2013, and twenty-year plan, Hellenic Republic, Ministry of Infrastructure, Transport and Networks, 2007.

13. National Port Policy (NPP) (2006), Hellenic Ministry, Ministry of Maritime Affairs, Islands and Fisheries, General Secretariat of Ports and Port Policy, 2006. 